\title{
The impact of foster care on development
}

\author{
CATHERINE R. LAWRENCE, ELIZABETH A. CARLSON, \\ AND BYRON EGELAND \\ University of Minnesota
}

\begin{abstract}
Foster care is a protective intervention designed to provide out of home placement to children living in at-risk home environments. This study employs prospective longitudinal data $(N=189)$ to investigate the effects of foster care on the development of child behavior and psychological functioning taking into account baseline adaptation prior to placement and socioeconomic status at the time of placement. Comparisons were made among three groups: children who experienced foster care, those who were maltreated but remained in the home, and children who had not experienced foster care or maltreatment despite their similarly at-risk demographic characteristics. In the current sample, children placed in out of home care exhibited significant behavior problems in comparison to children who received adequate care, and using the same pre- and postplacement measure of adaptation, foster care children showed elevated levels of behavior problems following release from care. Similarly, children placed into unfamiliar foster care showed higher levels of internalizing problems compared with children reared by maltreating caregivers, children in familiar care, and children who received adequate caregiving. Findings suggest that outcomes related to foster care may vary with type of care and beyond the effects associated with maltreatment history, baseline adaptation, and socioeconomic status.
\end{abstract}

The foster care social service system is designed to ameliorate adverse family and environmental conditions that may interfere with typical child development. Currently, the system provides short- and long-term out of home placement to children whose parents are deemed unable to care adequately for them. The effectiveness of foster care as an intervention, however, is the subject of controversy. Throughout the current foster care literature, removing children from their families of origin and placing them in out of home care has been associated with negative developmental consequences that place children at risk for behavioral, psychological, developmental, and academic problems (Curtis, Dale, Kendall, \&

Preparation of the work and the research described herein were supported by a National Institute of Mental Health grant (MN 40864) to Byron Egeland.

Address correspondence and reprint requests to: Byron Egeland, Institute of Child Development, University of Minnesota, 51 East River Road, Minneapolis, MN 55455; E-mail: egela001@umn.edu.
Rockefeller, 1999), although rigorous empirical investigations of the sequelae of foster placement are limited.

The current study addresses limitations in the existing literature by evaluating the direct effects of foster care on behavior problems within a prospective, longitudinal sample of high-risk children and their families. The study examines the impact of foster care on behavior problems and psychological functioning over and above risks associated with baseline developmental adaptation (prior to placement) and socioeconomic status (SES). We begin by reviewing the history and general characteristics of the foster care system, the potential developmental risks posed for children entering the system, and results of empirical studies related to foster care experience.

During 2001 it was estimated that 542,000 children resided in foster care (US Department of Health and Human Services, 2003). The need for foster placements presently exceeds available homes by $30-40 \%$ (US Department of Health and Human Services, 2003). 
Criteria for placing children into foster care are not well delineated. Entry is often associated with a history of child maltreatment perpetrated by the primary caregiver, failure of primary caregivers to protect children from maltreatment by others, parental chemical addiction, psychological or physical illness of the primary caregiver, homelessness, children's behavior problems, poor quality of the parentchild relationship, and parental abandonment of children (Arad, 2001; Curtis, 1999; Jones, 1985; United States General Accounting Office, 1995).

Proponents of foster care note that 70 $80 \%$ of children in out of home placements have been maltreated in the home of origin, and that prevention of further maltreatment is achieved in the majority of cases (Arad, 2001; Landsverk, 1996; Landsverk \& Garland, 1999). The likelihood of parental recidivism in the areas of physical abuse and neglect following reunification is reduced (Landsverk, 1996; Landsverk \& Garland, 1999; Zuravin \& DePanfilis, 1997), a noteworthy finding because $60 \%$ of children exiting foster care in recent years reunify with the preplacement parent and family (US Department of Health and Human Services, 2003).

\section{Developmental Context of Foster Care}

Developmental researchers recognize that it is often the association of multiple risk factors that derails the potential for positive developmental outcomes (Rutter, 1987). The resilience literature and cumulative risk models regard chronic poverty, disrupted and dysfunctional family situations, child maltreatment as well as foster placement as risks that heighten vulnerability to maladaptation and psychiatric disorder (Egeland, Carlson, \& Sroufe, 1993; Garmezy, 1993; Garmezy \& Masten, 1994; Masten \& Garmezy, 1985; Masten \& Wright, 1998; Rutter, 1987). Out of home care may be associated with a single or multitude of risks and/or chronic exposure to adverse circumstances within the context of the home environment (Masten \& Wright, 1998). In addition to these baseline risks, entry into foster care itself lies outside of the range of typical child- hood experience, further challenging already vulnerable children. Thus, while out of home care is intended to ameliorate adverse caregiving conditions, the accumulation of experiences necessitating placement often render children even more vulnerable to emotional and behavioral difficulties.

Maltreatment is a common preplacement experience that poses significant risk for poor developmental outcomes (Cicchetti \& Toth, 2000). Multifaceted negative sequelae include domains of school performance (Egeland, 1997), overall functioning (i.e., increased behavior problems; Egeland, 1991a; Egeland \& Sroufe, 1981), and psychopathology (Egeland, 1997). Children entering foster care with a history of maltreatment may be at increased risk. Research suggests that these children have endured more severe abuse and markedly inadequate care in comparison to maltreated children who do not come to the attention of social service providers. A related preplacement risk factor is problematic attachment formation (Carlson, 1998; Carlson, Cicchetti, Barnett, \& Braunwald, 1989; Egeland \& Sroufe, 1981; McCrone, Egeland, Kalkoske, \& Carlson, 1994). Differences in the quality of infant attachment organization are related to variations in caregiving experience during the first year of life (Ainsworth, Blehar, Waters, \& Wall, 1978; Bowlby, 1969/1982). Children who experience rejecting or insensitive care frequently come to expect parental unavailability, and are likely to develop behavioral patterns that have long-term negative consequences for socioemotional development (Egeland \& Carlson, 2004; Sroufe, 1996). Placement of children into foster care is often precipitated by failures within the caregiving environment. Moreover, foster care, by design, challenges caregiving relationships through extended caregiver-child separations during infancy and toddlerhood. For some children, separations may be experienced as significant rejection or loss, compounding a history of parental unavailability (Bowlby, 1960; Dozier, Stovall, Albus, \& Bates, 2001) and potentially distorting the child's adjustment to surrogate caregivers and the foster home environment (Cummings \& Cicchetti, 1990). 


\section{Sequelae of Foster Care}

A broad review of foster care research suggests that foster children deviate from typical development in all domains and are at significant risk for unusually high rates (30-80\%) of psychological and behavioral problems and special needs (Arad, 2001; Hochstadt, Jaudes, Zimo, \& Schachter, 1987; McIntyre \& Keesler, 1986; Rutter, 2000; Zima et al., 2000). Disparate methodologies employed by researchers and differing sample sizes, however, yield conflicting specific conclusions.

Early investigations of foster care employed a wide range of methodologies but commonly found that poor social functioning and emotional difficulties were the result of multiple placements during longer term stays in care (Theis, 1924; Weinstein, 1960). The negative impact of child behavior problems on foster parent-child relationships was thought to contribute to multiple placement changes (Maas \& Engler, 1959).

The first large-scale studies of the mental health issues of foster children in the United States reported frequent diagnoses of anxiety and/or depression among those in foster care (Shah, 1974; Swire \& Kavaler, 1977). Fanshel and colleagues (Fanshel, Finch, \& Grundy, 1989; Fanshel \& Shin, 1978) conducted the first longitudinal investigation of behavior problems in foster care children. In this sample $(N=585)$ behavior problems were present in $46 \%$ of children discharged from foster care at 1 year, and among 54\% remaining in foster care for 5 years or longer.

In response to the varying prevalence rates cited in past studies and general methodological problems related to the use of nonstandardized instruments, investigators have sought to assess foster children with norm-referenced measures of behavior problems completed by a parent or parental figure. Rates of behavior problems and clinically significant symptoms measured by the Child Behavior Checklist (CBCL; Achenbach \& Edelbrock, 1986) are reported as up to 2.5 times higher for children in foster care than for those of samples thought to share demographic characteristics but not entering protective custody (Hulsey and White, 1989; McIntyre and Keesler, 1986; Zima et al.,
2000). However, because these studies were based on foster parent report with varying degrees of contact with the participants (3 months to several years), it is difficult to evaluate whether findings were related to severity of symptoms, transient behavioral responses, or degree of familiarity between foster mother and child.

Controlling for degree of familiarity with the children, Clausen, Landsverk, Ganger, Chadwick, and Litrownik (1998) examined licensed foster parent CBCL reports during the first 2-4 months of foster care $(N=140)$. Fifty percent of the sample scored at or above the borderline clinical range, and over $40 \%$ had one subscale score in the clinical range. Although preplacement adaptation was not assessed, behavior problems and symptom levels may have been related to experience prior to entry into foster care.

Taking into account the timing of preplacement assessment, Armsden, Pecora, Payne, and Szatkiewicz (2000) documented the psychological functioning of 362 children ages 4-18 years just prior to placement in the foster care system. At intake, an adult deemed most familiar with the child (i.e., a recruited foster parent related to the child, caseworker, or relative other than the participant's parent) served as informant. For this sample, $30 \%$ of CBCL Total scores fell within the clinical range; however, a desire to influence the placement decision and differing levels of familiarity with the child may have contributed to response biases. Assessments of children "at intake" into foster care may not capture preplacement characteristics, instead measuring transient behaviors related to anticipation of entry into foster care.

Milan and Pinderhughes (2000) examined the incidence of internalizing and externalizing behavior of 32 children (ages 9-13 years) reported by foster mothers 1 month after entry into care. In this study, children who perceived their new relationships as being more affectively positive tended to be viewed by foster mothers as showing more relational and less internalizing behavior. Foster mothers who reported more symptomatic externalizing behavior reported less relational behavior in children in their care. Maltreatment severity was 
associated with decreased relational behavior and increased internalizing symptoms, but not to externalizing behavior. Milan and Pinderhughes suggest that such early placement symptom reports may be influenced by a variety of factors including habituated symptom patterns, developing foster parent-child relationship quality, as well as informant bias.

In summary, studies of children in foster care suggest that this population is at significantly heightened risk for behavior problems. The severity and frequency of behavior problems far exceed the norm for children reared at home with similarly adverse backgrounds. Moreover, children with significant behavior problems and clinical diagnoses are likely to remain in foster care for longer periods and are at significant risk for multiple placements due to the level of care required to adequately treat them (Fanshel \& Shin, 1978; Simms \& Halfon, 1994). Foster care studies also highlight a number of methodological considerations that restrict the interpretation of research findings and our understanding of the impact of the foster care system on development. These include the limited use of preplacement adaptation assessment, the range of informants (e.g., foster parent, relatives, social workers) with varying degrees of familiarity and interest in the child (Halfon, Mendonca, \& Berkowitz, 1995), and the lack of differentiation between kinship and unrelated caregiver placements.

\section{Current Research Design}

The present study employs prospective longitudinal data to address these research limitations. The study examines the relation between foster care placement and the development of behavior problems controlling for child adaptation prior to placement (baseline). The highrisk sample includes participants who entered the foster care system, those who remained with and were reared by caregivers who showed a continuous propensity for maltreating their children, and at-risk participants from the same sample who received adequate care from parental figures in terms of parenting style with no history of maltreatment or foster care experience. The study examines the following:

1. the impact of length of foster care placement as longer term placements that have been related to placement instability, number of placements to determine the relation between stability of placement and development of behavior problems, and age of first placement to determine a possible relation between age of placement and the subsequent development of behavior problems;

2. the direct impact of foster care on behavior problems, controlling for baseline adaptation and SES including a comparative evaluation of the behavior problems of maltreated children reared at home and children who received adequate parental care;

3 . change in pre- and postplacement adaptation through repeated measure design among the participants who experienced foster care and an examination of change in behavior problems over time among the maltreated participants and those who received adequate care;

4. difference in outcome for children placed in child protective service prescribed foster care versus care with an adult familiar to the child; and

5. long-term consequences of foster care on behavior problems, overall emotional health, and psychopathology in adolescence.

\section{Method}

\section{Participants}

The participants in this investigation included 189 children and families from the Minnesota Longitudinal Study of Parents and Children, a prospective study of families at risk because of poverty and associated factors such as low educational status, young age of mothers at the birth of the first child, and chronically unstable home environments (Egeland \& Brunquell, 1979). From the total sample of 189 children, three subgroups were identified: 46 children who entered the foster care system; 46 children who were maltreated but remained at home with the maltreating caregiver; 
Table 1. Foster, maltreated, and control group demographic characteristics

\begin{tabular}{llll}
\hline \hline & Foster & Maltreated & Control \\
\hline Total sample & $n=46$ & $n=46$ & $n=97$ \\
Gender (\% male) & 56 & 65 & 47 \\
Race (\% Caucasian) & 37 & 54 & 53 \\
SES & $44.24_{\mathrm{a}, \mathrm{b}}$ & $47.53_{\mathrm{a}, \mathrm{c}}$ & $52.73_{\mathrm{b} . \mathrm{c}}$ \\
Mother's age (mean years at child's birth) & 19.0 & 20.5 & 21.4 \\
Mother's education (mean grade at child's birth) & 10.76 & 11.53 & 12.30 \\
Elementary school subgroup & $n=15$ & $n=15$ & $n=15$ \\
Gender (\% male) & 60 & 60 & 60 \\
Race (\% Caucasian) & 30 & 56 & 40 \\
SES & $44.34_{\mathrm{d}}$ & 46.88 & $49.79_{\mathrm{d}}$ \\
Mother's age & 18.73 & 19.60 & 19.00 \\
Mother's education & 11.00 & 11.40 & 11.61 \\
\hline & Familiar & Unfamiliar & \\
\hline Foster care group & $n=23$ & $n=23$ & \\
Gender (\% male) & 53 & 52 & \\
Race (\% Caucasian) & 60 & 52 & \\
SES & 43.47 & 45.02 & \\
Mother's age & 18.69 & 18.95 & \\
Mother's education & 10.81 & 10.68 & \\
\hline \hline
\end{tabular}

Note: Means with the same subscript differ significantly at $p<.05$.

and 97 children who did not experience foster placement or maltreatment (see Table 1).

Foster care participants. The 46 foster care children were identified by reviewing interview data, life events inventories, and case summaries obtained during infancy, toddlerhood, preschool, kindergarten, and Grades 1, 2,3 , and 6 . Foster care group assignment required a minimum of 4 consecutive weeks of out of home placement. Overall, age of first placement ranged from birth to 9 years $(M=$ 4 years, 5 months); length of placement ranged from 1 to 45 months ( $M=13$ months); and number of placements ranged from 1 to 10 $(M=3)$. For the group placed into foster care during early elementary school (postkindergarten), mean length of placement was 25.76 months (range $=17-38$ months).

Entry into foster care was precipitated by maltreatment, death of a parent, parental incarceration, parental chemical addiction, or homelessness. Maltreatment accounted for $69 \%$ $(n=32)$ of foster care placement in this sample. Maltreatment history included neglect $(19 \%, n=6)$, physical abuse $(6 \%, n=2)$, psychological unavailability (emotionally un- responsive caregiving; $3 \%, n=1$ ), and maltreatment history of two or more categories (72\%, $n=23$, one of whom also experienced sexual abuse). Maltreatment severity ratings were not available for developmental periods examined in this study. However, the foster care and the maltreated groups did not differ on measures of adaptation prior to placement suggesting the possibility that maltreatment experienced was equivalent for both groups. Of the 46 children in out of home care, 23 were placed in unfamiliar foster care with adults unrelated and unknown to the child prior to placement (mean length of care $=16$ months, range $=1-45$ months). Children were also placed with familiar caregivers including: maternal and paternal grandparents, aunts and uncles, maternal significant others, and friends of the family (familiar foster care: $n=23$, mean length of care $=9$ months, range $=1-32$ months). Although our evidence of Child Protective Services (CPS) intervention in these cases was inconclusive, it appeared that approximately $40 \%$ of these placements were initiated by CPS involvement. All 46 children who entered foster care were intermittently or permanently reunited with biological care- 
givers during the course of this study. The overall foster care group included three subgroups: children first placed in foster care in the infancy/toddler period (0-24 months; $n=$ $14)$, in the preschool period (25-64 months; $n=17$ ), and during the elementary years (kindergarten, Grades 1, 2, 3, or 6; $n=15$ ).

Maltreatment participants. For the purpose of the current study, a subsample of 46 children who had experienced maltreatment between birth and sixth grade, but had not experienced foster care, was identified. These children were reared within their families of origin. Maltreatment was identified on the basis of laboratory and home observations and home interviews including the Child Care Rating Scale (Egeland \& Deinard, 1975) and questions regarding caretaking skills, feelings toward the child, and disciplinary practices.

Behaviors considered to be physically abusive ranged from frequent and intense spanking to unprovoked angry outbursts resulting in serious injuries (e.g., severe cigarette burns). In all instances, the abuse was seen as potentially physically damaging to the child. Mothers identified as hostile/verbally abusive chronically found fault with their children and engaged in constant berating and harassment. Caregivers considered to be psychologically unavailable were emotionally unresponsive to their children and, in many cases, passively rejecting of them. These mothers appeared detached and uninvolved (i.e., withdrawn, displaying flat affect, depressed), interacting with their children only when necessary. Caregiving neglect referred to the lack of responsible or competent management of day to day child care activities (e.g., health or physical care). Despite an expressed interest in their children's well-being, these caregivers seemed to lack the skill, knowledge, or understanding to provide consistent, adequate care. The validity of group placement was supported by Child Protection and Public Health records (Egeland, 1991b; Egeland \& Sroufe, 1981; Egeland, Sroufe, \& Erickson, 1983).

Maltreatment status was evaluated at three time points: infancy (birth to 24 months, $n=$ 14), the preschool years (25-64 months, $n=$ 17 ), and the elementary school years (kinder- garten, first, second, third, and sixth grades, $n=15$ ). Maltreatment time periods corresponded approximately to the developmental periods associated with foster care placement. Maltreatment history included physical abuse (37\%, $n=17)$, neglect $(13 \%, n=6)$, sexual abuse $(7 \%, n=3)$, and psychologically unavailable (emotionally unresponsive caregiving $13 \%, n=6)$. Thirty percent $(n=14)$ experienced two or more types of maltreatment (cf. Egeland \& Sroufe, 1981).

Control participants. Within the high risk sample, 97 control participants were identified. According to longitudinal study records (i.e., interviews, observations), these children had no history of maltreatment or foster care placement during the designated time periods.

\section{Measures}

Preplacement (baseline) measures. Baseline measures were selected to represent child functioning and developmental adaptation during infancy, toddlerhood, the preschool years, and kindergarten. For the foster care participants, these measures represented preplacement adaptation prior to entry into care. Assessments included (a) attachment quality (12-18 months), (b) toddler-caregiver experience rating (problem-solving task, 24 months), (c) persistence and ego control ratings (teach and barrier box tasks, respectively, 42 months), and (d) emotional health rank (teacher ranking, kindergarten). Baseline composite scores were derived from raw scores were converted to standard scores ( $z$ scores) and averaged. For example, in infancy, standardized attachment ratings were used as the baseline measure. For children placed or maltreated from 25 to 41 months of age, baseline scores consisted of standardized and averaged attachment and tool task ratings. For the control group the composite consisted of all available baseline assessment scores standardized and averaged.

Attachment assessment (12-18 months). Attachment was assessed at 12 and 18 months in the Strange Situation, a standardized laboratory procedure designed to assess infant pat- 
terns of attachment and exploration in relation to the primary caregiver (Ainsworth et al., 1978). Critical observations include infant exploration of the laboratory room, response to the mother's departure, response to the entry of a stranger, and reunion behavior with the mother. Infant-mother dyads were classified into four major categories: anxious/avoidant (A), secure (B), anxious/resistant (C), and disorganized (D). The validity and reliability of attachment classifications have been well documented (Ainsworth et al., 1978; Weinfield, Sroufe, Egeland, \& Carlson, 1999). Interrater agreements for $\mathrm{ABC}$ classifications for this sample were 89 and $93 \%$ (12 and 18 months, respectively). Interrater agreement for D classification was $86 \%$ based on 35 cases selected at random across 12 and 18 months $(\kappa=.72$; see Carlson, 1998). The baseline adaptation score used in the current study represented the number of assessments infants rated as secure $(0,1,2)$.

Problem-solving assessment (24 months). Child adaptation during the toddler period was assessed in a laboratory problem-solving situation consisting of four tasks designed to challenge toddler skill and emerging autonomy (Matas, Arend, \& Sroufe, 1978). Mothers were present and instructed to offer assistance only when necessary during the tasks. Based on videotaped observations, toddler experience with the caregiver in the session was rated on a 5-point scale. At the high end of the scale (5), children were judged to have had positive experiences (i.e., child responded to task in confident positive manner, drawing upon caregiver resources when necessary). At the low end of the scale (1), children were judged to have had markedly poor experiences, resulting from behavioral difficulties, failure to complete the tasks, and/or significant lack of support or conflict with the mother. This variable has been validated as a measure of child adaptation within the context of the relationship at this developmental period (Erickson, Sroufe, \& Egeland, 1985). Interrater reliability (intraclass correlation) was .87 $(N=185)$.

Teaching task assessment (42 months). At age 42 months, child functioning was assessed in the context of a parent-child teaching task. A series of four tasks including: block building, naming objects, matching colors and shapes, and tracing were presented, and mothers were instructed to offer any level of guidance or assistance deemed necessary. Child persistence (i.e., a critical quality in adverse circumstances) was rated using a 7-point Likert-style scale. At the high end of the scale (7), children demonstrated competent, goal-oriented problem-solving behavior regardless of the mother's emotional support. Low ratings (1) were assigned for active avoidance of the task as a result of attentional or behavioral difficulties, and/or interactional difficulties with the mother. Assessments were rated by two independent observers. The Persistence rating has been related positively to child response to challenge and negatively to distractibility and behavioral difficulties that interfere with social and academic functioning (Pianta, Erickson, Wagner, Kreutzer, \& Egeland, 1990). Interrater reliability (intraclass correlation) was $.88(n=87$; Egeland et al., 1983).

Barrier box (42 months). Child behavior independent of caregiver presence and assistance in the early childhood period was examined in response to a barrier box challenge task (Harrington, Block, \& Block, 1978). Children were presented with a latched, Plexiglas box containing attractive toys following the potentially frustrating removal of the identical, desirable toys from the assessment room. Ego control, the ability to control impulses or affect-laden emotion in the face of frustration, was rated on a 7-point Likert-type scale based on videotaped observations. At the high end of the scale (7), there was no evidence of overt frustration nor was there evidence that children were attempting to suppress frustration. A rating of 1 , at the low end of the scale, suggested that children became frustrated, angry, or panicked in response their emotion. The ego control rating was selected to represent young children's capacities to regulate emotion and impulses in challenging situations. This variable has been validated as an index of coping in response to frustration, and it discriminates maltreatment and control group functioning (Egeland et al., 1983; Pianta, 
Sroufe \& Egeland, 1989). Interrater reliability (intraclass correlation) was .86 $(n=60)$.

Emotional health ranking (kindergarten). Participant teachers were asked to rank order students in accordance with a written description of an "emotionally healthy child" without awareness of the research target child. The emotional health ranking assessed child confidence, curiosity, self-assuredness, enjoyment, and involvement. Scores were computed as ratios of the child's rank order standing (Connolly \& Doyle, 1981). This measure has been related in expected directions to concurrent ratings of behavior problems and peer competence (Heister, Carlson \& Sroufe, 1993). Reliability data were not available for the assessment (due to individual teacher rankings); however, rankings were found to be stable across elementary years, and interrater reliability coefficients ranged from .63 to .81 on similar child rank orders completed by multiple project counselors.

CBCL-Teacher's Report Form (CBCL-TRF; kindergarten). The CBCL-TRF was completed by participants' teachers at the end of the school year (Achenbach \& Edelbrock, 1986). The kindergarten assessment served as baseline measure for a subsample of participants. The TRF consists of 113 items rated by the teacher on a 3-point scale reflecting presence, frequency, and severity of the problem $(2=$ often $/$ very true, $1=$ sometimes or somewhat true, $0=$ not true). TRF items were constructed to evaluate a broad range of behavior problems and symptoms associated with psychopathology. Externalizing (i.e., aggressive and delinquent behavior, $\alpha=.82$ ), Internalizing (i.e., somatic complaints, withdrawn, and anxious/depressed behavior, $\alpha=.63)$ and Total $(\alpha=.79) T$ scores were used in the current study. The TRF was norm referenced on a sizeable representative national sample. The clinical range is defined as $1.5 S D$ above the mean. For the current sample, $T$ scores above 60 were regarded as within the clinical range.

SES (time of placement). The SES of participant families of origin was assessed using the
Duncan Socioeconomic Index in the prenatal period, at 16, 42, and 54 months, and in Grades $1,2,3$, and 6. The SES at time of placement for foster care participants was used to capture the most current SES for the family prior to placement. For the comparison group maltreatment time period was used as the basis for the socioeconomic index score. Grade 1 SES was used for all control participants.

\section{Outcome measures}

Specific outcome measures were selected to represent foster care child functioning immediately following (or close to) release from care. For maltreated participants, timing of outcome measures was selected based on time of release of the corresponding foster care group. Sixth grade measures were used as the outcome assessment for the control group.

CBCL-TRF (Grades 1, 2, 3, 6, 10). The CBCLTRF was completed by participant teachers at the end of the school year (Achenbach \& Edelbrock, 1986; see description above). Assessments at Grades 1, 2, 3, 6, and 10 served as outcome measures.

Kiddie Schedule for Affective Disorders and Schizophrenia Rating (17.5 years; KSADS). In adolescence, participants were administered the KSADS-III-R (Ambrosini, Metz, Prabucki, \& Lee, 1989; Puig-Antich \& Chambers, 1978), a semistructured interview designed to evaluate psychopathology. The interview yields diagnostic information as well as present and past symptoms of psychopathology. The test-retest reliability within a 3-day period varied by diagnosis, but it remained in the moderate range (Chambers et al., 1985). Various forms of the measure have been extensively validated through reassessment of clinical patients with known diagnoses and by examining treatment and biological correlates of specific diagnoses (Costello, 1991). Interrater reliability (mean $\kappa=.79$ for childderived diagnoses) of the KSADS-III-R was reported by Ambrosini and colleagues (1989) based on present symptom information. For the current study, a 7-point Likert-style rating scale was employed to quantify the number 
and severity of present and past diagnoses. Participants with five or more distinct severe diagnoses were rated 7 . At the low end of the scale, a rating of 2 signified one minor diagnosis such as simple phobia, and a rating of 1 indicated no past or present diagnosis. Interrater reliability (intraclass correlation) for the current sample was .94 $(n=35)$.

\section{Data analysis}

Five sets of analyses were conducted: preliminary correlations, analysis of covariance (ANCOVA) to examine group differences in behavior problems with baseline adaptation and SES as covariates, repeated measures ANCOVA to examine changes in behavior problems over time, analysis of variance (ANOVA) examining the effects of unfamiliar and familiar care, and ANCOVA to examine the longterm effects of foster care on emotional health and psychopathology diagnoses.

\section{Results}

\section{Preliminary analyses}

Preliminary analyses examined the correlations between the baseline adaptation score (adaptation prior to placement for foster care group), SES, and outcome measures (TRF at release from care and Grade 6). Because both baseline adaptation scores $(r=-.25, p<.01$; $r=-.19, p<.05)$ and SES measures $(r=$ $-.17, p<.05 ; r=-.20, p<.01)$ were significantly correlated with outcome measures, baseline adaptation scores and SES at time of placement served as covariates in subsequent analyses. Length of time in care, age of placement into care, and child protective service involvement were not correlated with outcome measures. An ANOVA revealed statistically significant group differences in baseline adaptation score, $F(2,181)=5.75, p<.01$. Foster care and maltreatment groups each differed significantly from the control group in post hoc analyses $(t=-2.45, p<.01 ; t=$ $-2.22, p<.05$, respectively). The findings suggest that prior to placement children entering foster care and a comparable maltreated group exhibited poor adaptation (i.e., more behavior problems) in comparison to the control group. The foster care and maltreated groups did not differ significantly with respect to baseline developmental adaptation.

A series of partial correlations was conducted to determine whether the age of first placement into foster care, length of time in placement, and number of placements were related to behavior problems (TRF) at release from foster care controlling for baseline adaptation and SES at time of placement. Length and stability of care, and age of entry into care were not significantly correlated with the TRF indicator of behavior problems $(r=.13, .16$, and $.09 ; n s$, respectively). Participants whose care was arranged by county social services did not differ from those whose care was arranged without documented evidence of county services involvement in placement.

\section{Principal analyses}

To examine the direct impact of foster care on the development of behavior problems, a series of one-way ANCOVAs was conducted. Analyses were designed to test whether the three groups (foster care, maltreated, and control) differed with respect to TRF score at release from care controlling for baseline adaptation and SES at time of placement. The analyses investigated whether foster care directly impacted the development of behavior problems above the risks associated with baseline adaptation, SES, and child maltreatment. ANCOVA results indicated significant overall group mean differences in TRF total and externalizing scores at release from foster care controlling for baseline adaptation and SES (see Table 2). Post hoc contrasts revealed significant differences between the foster care and the control groups on both TRF total and externalizing scores $(t=2.36, p<.05 ; t=$ 3.16; $p<.01$, respectively). Post hoc tests also indicated significant differences in TRF Externalizing (but not Total) scores between the maltreated and control groups $(t=2.60$; $p<.01)$. Foster care and maltreated group TRF total and externalizing scores did not differ significantly. The results of the Internalizing Scale analyses were not significant (see Table 2). 
Table 2. Adjusted means, standard deviations, and analysis of covariance results for TRF total, externalizing, and internalizing at release from foster care as a function of baseline adaptation and SES

\begin{tabular}{|c|c|c|c|c|c|c|c|}
\hline \multirow[b]{2}{*}{ Variable } & \multicolumn{2}{|c|}{$\begin{array}{l}\text { Foster Care } \\
\quad(n=39)\end{array}$} & \multicolumn{2}{|c|}{$\begin{array}{l}\text { Maltreated } \\
(n=42)\end{array}$} & \multicolumn{2}{|c|}{$\begin{array}{l}\text { Control } \\
(n=95)\end{array}$} & \multirow{2}{*}{$\begin{array}{l}\text { ANCOVA } \\
F(2,173)\end{array}$} \\
\hline & $M$ & $S D$ & $M$ & $S D$ & $M$ & $\overline{S D}$ & \\
\hline Total score TRF & $58.58_{\mathrm{a}}$ & 10.79 & 56.75 & 10.39 & $53.91_{\mathrm{a}}$ & 9.09 & $3.07 *$ \\
\hline Externalizing TRF & $59.40_{\mathrm{b}}$ & 10.26 & $57.95_{c}$ & 9.52 & $53.74_{\mathrm{bc}}$ & 9.49 & $5.06 * *$ \\
\hline Internalizing TRF & 54.64 & 10.76 & 52.92 & 10.69 & 54.41 & 8.91 & .46 \\
\hline
\end{tabular}

Note: Means with the same subscript differ significantly. $* p<.05 . * * p<.01$.

To further examine group differences, a subsample of participants placed into foster care during the early elementary school years (Grades $1-3)$ was identified $(n=15)$. For this subset, TRF total scores served as both baseline (kindergarten) and postplacement measures (immediately following release from foster care), permitting pre- and postplacement comparisons on the same measure of behavior problems. Corresponding maltreated and control groups were constructed for the analyses. The $3 \times 2$ (Group $\times$ Change) repeated-measure ANOVA examining change in TRF total scores was significant (see Table 3). The Group $\times$ Change interaction was also significant. Post hoc comparison of change scores indicated a significantly greater rise in scores within the foster care group than within the maltreated group $(t=1.74, p<$ .05). Repeated-measure ANOVA examining change in TRF externalizing and internalizing scores were also significant (see Table 3). Group $\times$ Change interactions were significant as well. Post hoc analyses indicated that the rise in the foster care externalizing and internalizing scores differed significantly from the change in the maltreatment group scores $(t=1.93, p<.05 ; t=3.62, p<.001$, respectively). The foster care group rise in externalizing scores also significantly exceeded that of the control group $(t=1.96, p<.05)$. The findings suggest that the externalizing and internalizing behavior problems of children in foster care increased significantly between baseline assessment and subsequent measurement immediately following release from care.
For 13 of the 15 children, behavior problems were also assessed while in care. After controlling for baseline adaptation and SES, "in care" TRF total scores differed significantly, $F(2,37)=3.39, p<.05$. Post hoc analyses indicated that the foster care group differed significantly from both the maltreated and control groups $(t=2.10, p<.05 ; t=$ $2.91 ; p<.05$, respectively). Descriptive statistics were as follows: foster care: $M=63.84$, $S D=11.96$; maltreated: $M=54.92, S D=$ 11.62; control: $M=52.76, S D=7.45$.

The effects of unfamiliar versus familiar foster care on the development of behavior problems were examined controlling for baseline adaptation and SES at the time of placement. ANCOVA results indicated significant overall group mean differences on TRF Total, Externalizing, and Internalizing scores at release from care (see Table 4). Post hoc analyses indicated that unfamiliar and familiar foster care groups differed with respect to Internalizing $(t=3.11, p<.001)$, but not Externalizing or Total score. Children in unfamiliar foster care exhibited higher internalizing, but not externalizing or total TRF scores following release from care. Unfamiliar foster care and control groups differed significantly with respect to Total $(t=2.75, p<.01)$ and Externalizing $(t=2.92, p<.001)$ scores.

To examine the long-term effects of foster care on behavior, a $3 \times 2$ repeated-measure ANCOVA (Group $\times$ Assessment Period) was conducted on the entire sample with baseline adaptation and SES at time of placement controlled (see Table 5). Changes in TRF scores 
Table 3. Means, standard deviations, and repeated measure analysis of variance for change in TRF scores among participants placed into foster care during the early elementary school years

\begin{tabular}{|c|c|c|c|c|c|c|c|}
\hline \multirow[b]{2}{*}{ Variable } & \multicolumn{2}{|c|}{$\begin{array}{l}\text { Foster Care } \\
\quad(n=15)\end{array}$} & \multicolumn{2}{|c|}{$\begin{array}{l}\text { Maltreated } \\
(n=15)\end{array}$} & \multicolumn{2}{|c|}{$\begin{array}{l}\text { Control } \\
(n=15)\end{array}$} & \multirow{2}{*}{$\begin{array}{l}\text { ANCOVA } \\
F(2,173)\end{array}$} \\
\hline & $M$ & $S D$ & $M$ & $S D$ & $M$ & $S D$ & \\
\hline \multicolumn{8}{|l|}{ TRF total score } \\
\hline Preplacement & 52.80 & 11.34 & 55.86 & 8.22 & 43.33 & 9.19 & \\
\hline Postplacement & 61.00 & 7.69 & 57.66 & 10.46 & 47.66 & 7.94 & \\
\hline Change & $8.20_{\mathrm{a}}$ & 9.69 & $1.80_{\mathrm{a}}$ & 10.40 & 4.33 & 9.37 & \\
\hline Between group & & & & & & & $9.34 * *$ \\
\hline Group $\times$ Change & & & & & & & $2.29 *$ \\
\hline \multicolumn{8}{|l|}{ TRF externalizing } \\
\hline Preplacement & 52.73 & 10.08 & 56.53 & 10.35 & 45.66 & 9.29 & \\
\hline Postplacement & 61.60 & 8.55 & 58.06 & 9.47 & 48.26 & 9.83 & \\
\hline Change & $8.87_{\mathrm{bc}}$ & 10.78 & $1.53_{\mathrm{b}}$ & 10.13 & $2.60_{c}$ & 8.99 & \\
\hline Between group & & & & & & & $8.26 * *$ \\
\hline Group $\times$ Change & & & & & & & $2.64 *$ \\
\hline \multicolumn{8}{|l|}{ TRF internalizing } \\
\hline Preplacement & 47.80 & 10.34 & 54.53 & 8.77 & 44.00 & 7.66 & \\
\hline Postplacement & 58.13 & 7.76 & 54.33 & 8.64 & 49.40 & 10.60 & \\
\hline Change & $10.33_{\mathrm{d}}$ & 6.73 & $-.20_{\mathrm{d}}$ & 9.03 & 5.40 & 8.44 & \\
\hline Between group & & & & & & & $6.30 * *$ \\
\hline Group $\times$ Change & & & & & & & $3.34 *$ \\
\hline
\end{tabular}

Note: Means with the same subscript differ significantly.

$* p<.05 . * * p<.01$.

Table 4. Adjusted means, standard deviations, and analysis of covariance results for TRF total, externalizing, and internalizing scores at release from care of unfamiliar and familiar foster care, abuse, and control as a function of baseline adaptation and SES

\begin{tabular}{|c|c|c|c|c|c|c|c|c|c|}
\hline \multirow[b]{2}{*}{ Variable } & \multicolumn{2}{|c|}{$\begin{array}{l}\text { Unfamiliar } \\
(n=19)\end{array}$} & \multicolumn{2}{|c|}{$\begin{array}{l}\text { Familiar } \\
(n=20)\end{array}$} & \multicolumn{2}{|c|}{$\begin{array}{l}\text { Maltreated } \\
(n=42)\end{array}$} & \multicolumn{2}{|c|}{$\begin{array}{c}\text { Control } \\
(n=95)\end{array}$} & \multirow{2}{*}{$\begin{array}{l}\text { ANCOVA } \\
F(2,173\end{array}$} \\
\hline & $M$ & $S D$ & $M$ & $S D$ & $M$ & $S D$ & $M$ & $S D$ & \\
\hline Total score TRF & $61.29 \mathrm{a}$ & 12.31 & 56.04 & 8.77 & 56.75 & 10.39 & $53.91_{\mathrm{a}}$ & 9.09 & $3.04 *$ \\
\hline Externalizing TRF & $60.42_{\mathrm{b}}$ & 11.03 & 58.37 & 10.21 & 57.95 & 9.52 & $53.74_{\mathrm{b}}$ & 9.49 & $3.31 *$ \\
\hline Internalizing TRF & $59.47_{\mathrm{c}}$ & 12.38 & $50.12_{c}$ & 9.64 & 52.92 & 10.69 & 54.41 & 8.91 & $3.87^{*}$ \\
\hline
\end{tabular}

Note: Means with the same subscript differ significantly. ${ }^{*} p<.05$.

at release from foster care, sixth grade, and during high school at age 16 were analyzed for within subject and between group differences and for interactions. There was no significant main effect across time period; however, between group differences were statistically significant for Total and Externalizing scores. Repeated Measure $\times$ Group interactions were not significant.
Additional analyses of covariance examined the long-term effects of foster care on an overall Index of psychopathology at age 17.5 years (see Table 6). Controlling for baseline adaptation and SES, the ANCOVA examining psychopathology diagnoses was significant with the foster care and maltreated groups differing from the control group $(t=1.96, p=$ $.05 ; t=2.95, p<.01)$. 
Table 5. Adjusted means, standard deviations, and results of repeated measure analysis of covariance for TRF total, externalizing, and internalizing scores at release from foster care, Grade 6, and age 16 as a function of baseline adaptation and SES

\begin{tabular}{|c|c|c|c|c|c|c|c|}
\hline \multirow[b]{2}{*}{ Variable } & \multicolumn{2}{|c|}{$\begin{array}{l}\text { Foster Care } \\
\quad(n=30)\end{array}$} & \multicolumn{2}{|c|}{$\begin{array}{l}\text { Maltreated } \\
(n=39)\end{array}$} & \multicolumn{2}{|c|}{$\begin{array}{l}\text { Control } \\
(n=88)\end{array}$} & \multirow{2}{*}{$\begin{array}{l}\text { ANCOVA } \\
F(2,154)\end{array}$} \\
\hline & $M$ & $S D$ & $M$ & $S D$ & $M$ & $S D$ & \\
\hline \multicolumn{8}{|l|}{ TRF total score } \\
\hline Release from care & $58.53_{\mathrm{a}}$ & 11.11 & 57.43 & 10.77 & $53.47 \mathrm{a}$ & 8.71 & \\
\hline Grade 6 & $58.33_{\mathrm{b}}$ & 9.40 & 58.25 & 8.61 & $53.47_{\mathrm{b}}$ & 8.71 & \\
\hline Age 16 & $59.03_{\mathrm{c}}$ & 9.72 & 56.30 & 9.20 & $54.44_{c}$ & 8.05 & \\
\hline Between group & & & & & & & $3.28 *$ \\
\hline Repeated Measure $\times$ Change & & & & & & & 0.95 \\
\hline \multicolumn{8}{|l|}{ TRF externalizing } \\
\hline Release from care & $58.86_{\mathrm{d}}$ & 10.83 & 58.38 & 9.82 & $53.64_{d}$ & 9.16 & \\
\hline Grade 6 & $57.83_{\mathrm{e}}$ & 9.49 & 58.56 & 9.99 & $53.64_{\mathrm{e}}$ & 9.16 & \\
\hline Age 16 & $58.13_{\mathrm{f}}$ & 10.44 & 56.89 & 9.64 & $54.85_{\mathrm{f}}$ & 8.20 & \\
\hline Between group & & & & & & & $3.91 *$ \\
\hline Repeated Measure $\times$ Change & & & & & & & 0.88 \\
\hline \multicolumn{8}{|l|}{ TRF internalizing } \\
\hline Release from care & 54.33 & 10.56 & 53.41 & 11.09 & 53.57 & 8.07 & \\
\hline Grade 6 & 55.76 & 10.49 & 57.28 & 8.49 & 53.57 & 8.07 & \\
\hline Age 16 & 56.53 & 9.87 & 54.61 & 8.36 & 52.84 & 7.76 & \\
\hline Between group & & & & & & & 0.18 \\
\hline Repeated Measure $\times$ Change & & & & & & & 1.64 \\
\hline
\end{tabular}

Note: Means with the same subscript differ significantly. $* p<.05$.

Table 6. Adjusted means, standard deviations, and analysis of covariance results for psychopathology diagnostic ratings (age 17.5 years) as a function of baseline adaptation and SES

\begin{tabular}{|c|c|c|c|c|c|c|c|c|}
\hline \multirow[b]{2}{*}{ Variable } & \multicolumn{2}{|c|}{$\begin{array}{l}\text { Foster Care } \\
\quad(n=32)\end{array}$} & \multicolumn{2}{|c|}{$\begin{array}{l}\text { Maltreated } \\
(n=37)\end{array}$} & \multicolumn{2}{|c|}{$\begin{array}{c}\text { Control } \\
(n=88)\end{array}$} & \multicolumn{2}{|c|}{ ANCOVA } \\
\hline & $M$ & $S D$ & $M$ & $S D$ & $M$ & $S D$ & $F$ & $d f$ \\
\hline Psychopathology & $3.53_{\mathrm{a}}$ & 1.98 & $3.83_{b}$ & 1.90 & $2.80_{\mathrm{ab}}$ & 1.73 & $3.41 *$ & 2,154 \\
\hline
\end{tabular}

Note: Means with the same subscript differ significantly. $* p<.05$.

Trajectories of foster care, maltreated, and control group adaptation ( $z$ scores) from preplacement, or baseline, to release from care and at ages 16 and 17 are depicted in Figure 1. For subsets of the three groups, trajectories of TRF Total scores from baseline to age 16 are depicted in Figure 2. Assessment periods include baseline, in care, release of from, age 11 and age 16.

\section{Discussion}

This study examined the impact of foster care placement on the development of behavior problems within the context of a prospective multimethod, multiple informant longitudinal design. The consequences of foster care placement were evaluated immediately following release from care and at several points later in 


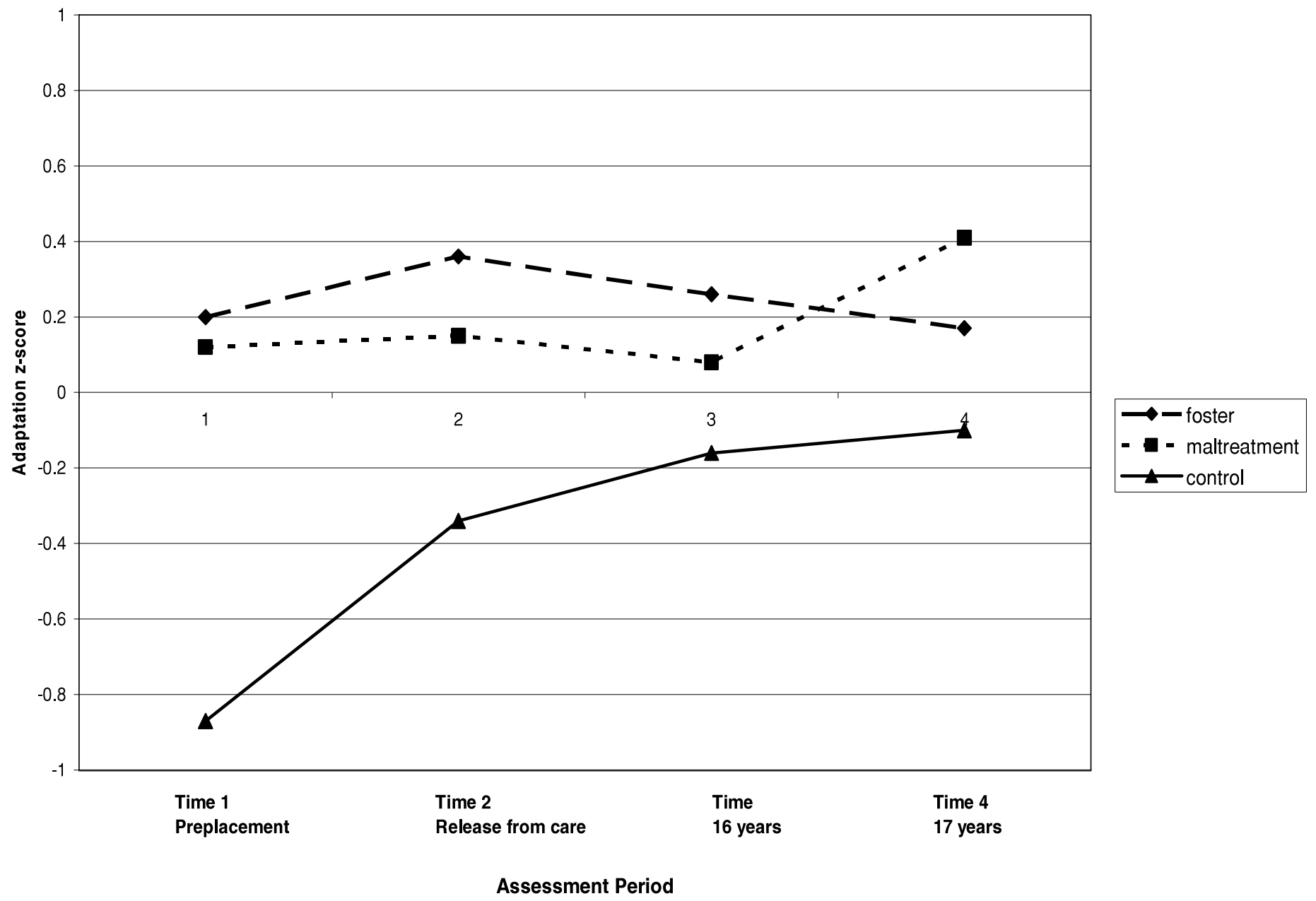

Figure 1. Adaptation $z$ scores for preplacement, release from care, 16- and 17-year assessments for foster care $(n=46)$, maltreatment $(n=46)$, and control $(n=$ 97) groups. 


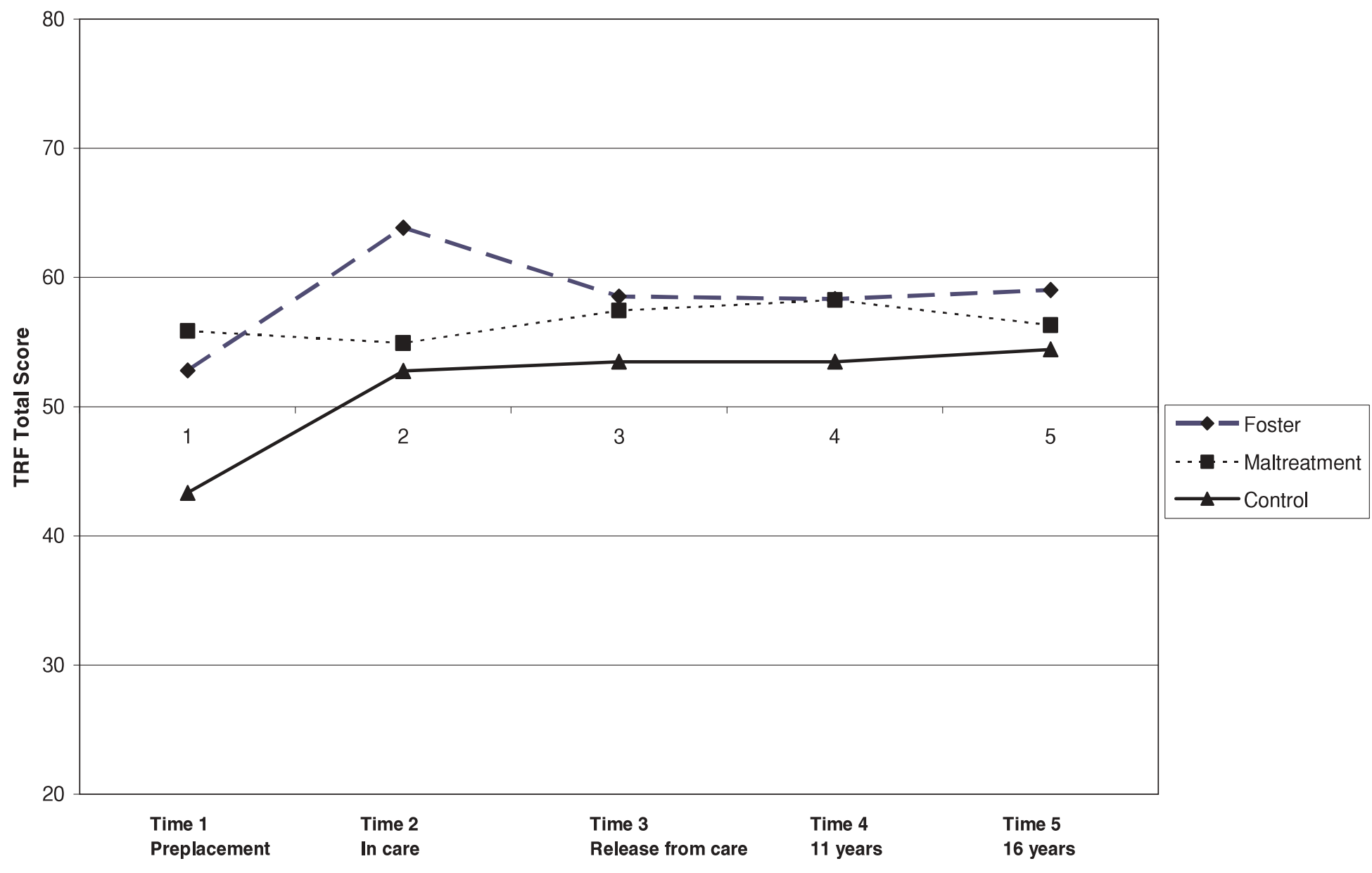

Time Period

Figure 2. Teacher Report Form (TRF) total scores from preplacement to 16 years of foster care, maltreatment, and control groups $(n=15 /$ group). 
development. Controlling for developmental adaptation and SES prior to placement, the results support a general view that foster care may lead to an increase in behavior problems that continues after exiting the system. An attempt to determine the extent to which foster care influences development is an important process as foster care necessitates a significant disruption in the caretaking environment of children who have likely experienced adverse circumstances prior to placement.

Initial analyses suggest that for the current sample, length of time in care, age of first placement, and the risks associated with multiple placements were found to be unrelated to the development of behavior problems. County protective service involvement also did not relate to behavior problems. With baseline adaptation and SES at time of placement removed to control for preexisting influences, findings suggest that children who experienced foster care displayed higher levels of behavior problems immediately following release from care compared to children who received adequate parental care within disadvantaged home environments. The behavior problems of children who had left foster care continued to be elevated during adolescence above levels exhibited by children who had experienced adequate parental care. Analyses of the entire sample did not differentiate the risks associated with foster care placement from those remaining with the family of origin and a maltreating caregiver.

Analysis of children placed into care after kindergarten permitted the examination of preand postplacement change in behavior problems assessed with the same measure (TRF). In these analyses, the foster and maltreated groups did not differ prior to placement. However, immediately following placement, children in foster care exhibited an increase in behavior problems. The increase in problematic behavior following departure from foster care significantly exceeded change in behavior problems among those reared by maltreating parental figures, suggesting an exacerbation of problem behavior in the context of out of home care. The assessment of behavior problems of a small sample of participants $(n=$ 13) while in care also suggested significantly elevated levels during their time in care. Incare behavior problems significantly exceeded those of the maltreated and control comparison groups assessed during the same developmental periods. These findings are especially compelling considering that outcomes were obtained from measures that eliminate biases in previous studies relying on foster parents or social workers as informants.

An additional subgroup analysis examined the extent to which unfamiliar and familiar foster care experiences influenced the development of subsequent behavior. Unfamiliar foster care arranged by CPS was provided by an unfamiliar and unrelated caregiver. Familiar care was arranged with a known caregiver (often a relative or family friend). Based on available project records, a minimum of $40 \%$ of familiar care cases were precipitated by social service intervention. Although children in unfamiliar foster care may have been expected to show higher levels of maladaptation prior to entry into care, assuming that they had come to the attention of social services due to markedly adverse family contexts, unfamiliar and familiar foster children did not differ with respect to baseline adjustment in this sample. Type of foster care experience, however, did differentiate behavior problem status immediately following release from foster care. Internalizing behavior problems among children exiting unfamiliar foster care significantly exceeded those of children exiting familiar care, also exceeding those of the maltreated home-reared group and adequately cared for children.

Analyses to examine the extent to which foster care experience impacts psychopathology diagnoses during adolescence (with baseline adaptation and SES controlled) also revealed significant differences between both the foster care and maltreated groups and the control group (with no significant distinction between foster care and maltreatment psychopathology indices).

Despite the expectations that length of time in foster care and placement instability would be associated with the development of behavior problems, no statistically significant relations were found in the present study. Length of time in care, age of first placement, the 
risks associated with multiple placements and the involvement of county protective services were found to be unrelated to the development of behavior problems. These findings deviate from past research suggesting that multiple placements in longer term care pose a risk for poor outcomes (McDonald, Allen, Westerfelt, \& Piliavin, 1996). It is possible that the small sample size of the current study did not generate significantly meaningful relations between these qualitative aspects of the foster care experience and subsequent behavior. Length of time in care and the influence of multiple placements are important qualitative measures of the foster care experience. Within a larger sample, these salient factors may prove to be more powerful predictors of behavior problems and related outcomes.

In the current study, the heightened behavior problem levels manifested in children in care and immediately following release from foster care raise cautious concern regarding the impact of foster care on development. Although based on small samples, this study controlled for baseline developmental adaptation (prior to placement) and the risks associated with low SES, ruling out the possibility that differences between foster care and control participants were due to differences in initial adaptation.

Several factors may account for the increase in problematic behavior associated with out of home care. First, foster care as an intervention may expose its recipients to difficult developmental challenges. For example, separation from primary caregivers in the context of placement with unfamiliar adults may pose an especially difficult challenge for very young children. Second, although not a reflection on specific foster caregivers, the relations may reflect weaknesses within the foster care system: the school, social, and familial changes that foster care placement often entails; the lack of comprehensive psychological services offered to foster children; as well as often inadequate training and support services for foster parents. It is also possible that the ambiguity of the placement experience with no delineated endpoint or stated outcome may contribute to children's emotional difficulties in processing the experience as well as caregiver commitment to the children.
Unfamiliar versus familiar foster care outcome differences (e.g., higher level internalizing problems) further suggest that facets of the foster care experience may be challenging to children. Although it is difficult to generalize from this relatively small sample, it is possible that familiar care with relatives or familiar figures presents an environment that necessitates fewer changes in caregiving routine, social milieu, and school environment. It may be that the availability and suitability of relatives to provide familiar foster care influence the type of care a child receives to a greater extent than mitigating factors that precipitated placement. It should also be acknowledged that familiar care arrangements may permit ongoing contact between biological mother and child changing the dynamic of the separation experience. This appears especially relevant in the context of the current study because the unfamiliar and the familiar care recipients did not differ on a measure of baseline developmental adaptation. The availability of suitable caregivers within a family network may serve as a protective factor in that children have familiar adult resources to draw upon for support possibly reducing experiences of anxiety, depression, and withdrawal.

Long-term effects of foster care were also investigated in the current study. One interpretation of these findings is that foster care itself may have a direct impact on the long-term increase in behavior problems. However, because maltreated and foster care children did not differ with respect to behavior problems, it is difficult to interpret whether the foster care experience itself or aspects of the intervening years (e.g., intermittent or permanent reunion with caregivers) influenced this finding. It is unclear whether further exposure to risk factors within the home environment or the lingering impact of foster care placement influenced long-term outcomes.

\section{Methodological Considerations}

As previously noted, the small sample size of the current study is a clear limitation, as it is difficult to generalize findings to larger populations and to find statistical associations among variables that may in fact represent 
important associations within the general population. The small sample size, differing lengths of placement, and varying ages of entry into care also made it unfeasible to assess enough children during their stays in foster care to render meaningful conclusions. Similarly, the differing ages of entry into care and lengths of time spent in foster care limit speculation regarding points in development and placement lengths that could potentially benefit those in care. Differing ages of entry into care in the current study also restricted the range of appropriate and available baseline adaptation measures that could be selected for the children placed earliest in development. Despite these limitations, the current study illustrated some methodological improvements over previous investigations. Most previous studies have not included measures of baseline developmental adaptation to evaluate the effects of the foster care experience. Similarly, the opportunity to evaluate differences among groups of children, including those who had experienced foster care, maltreated nonfoster children, and children who received adequate caregiving within their families of origin, was a clear advantage of the present study. A final benefit of this study was the use of teachers as informants, eliminating differing degrees of familiarity and any related unfamiliar and familiar foster parent biases regarding the children.

\section{Future Research and Policy Implications}

Evaluation of the strengths and limitations of the current study suggests a variety of improvements for future investigations. There is need for a large-scale systematic examination of children at risk for entering foster care (within a county or specific geographic region) with assessments conducted in advance of placement with ongoing, frequent follow-up. The current study illustrates the importance of examining adaptation as well as risk status prior to placement to more clearly define the impact of the foster care experience. A largescale investigation would be enhanced by the development of a consistent battery of baseline measures to be administered to all potential participants. Several of these measures could also be used as outcome measures to directly examine change following the foster care experience. It is also important for future research to focus on the effects of unfamiliar versus familiar foster care as well as the relative impact of the age or developmental status of the children when placed in out of home care. This research could examine the extent to which children in differing types of care have ongoing contact with their biological caregivers and the impact of this contact on children in care. Additional factors that may contribute to developmental risk for children in foster care require investigation. These include (a) the child's experience of separation and ambiguity of placement (lack of clarity with respect to parental reunification or custody termination); (b) the child's expectations, attitudes, and feelings regarding relationships derived from relationship history; (c) the instability, quality and type of care provided; and (d) the relationship history and experience of the caregiver.

Ongoing research with foster care providers may shed light on some of these issues and provide direction for policy and intervention (Dozier, 2002; Dozier, Stovall, \& Albus, 1998). Studies based on attachment theory and research suggest that routinely sensitive care may be insufficient for children with histories of grossly inadequate care. Severe histories of maltreatment and loss are associated with a range of maladaptive behaviors as well as distortions in representations of self and others in relationships (Cicchetti \& Toth, 2000; Lynch \& Cicchetti, 1991; McCrone et al., 1994). Foster caregivers may require training to recognize and respond therapeutically to the signals and special needs of foster children.

Policy implications of developmental research on the impact of foster care services are numerous. Research investigating the effects of timing of foster care entry may inform policy regarding types of services, transitional allowances, and care offered to meet the developmental needs of children entering foster placement at different points from infancy to adolescence. Research may guide foster parent training and inform policy regarding long-term placement planning (e.g., developmental timing, duration). Targeted research 
may also indicate whether therapeutic foster care settings with specific treatment goals would serve the complex purposes of protecting children and ameliorating past circumstances.

Policymakers must continue to address the issues of family reunification service and support for children receiving care and work toward increased funding for foster care services. It is recognized anecdotally that attempts to assist and treat parents while their children are in foster care are often ineffectively executed, increasing the likelihood of recidivism and future placements. Similarly, support for chil-

\section{References}

Achenbach, T., \& Edelbrock, C. (1986). The Child Behavior Checklist-Teacher's Report Form. Burlington, VT: Department of Psychiatry, University of Vermont.

Ainsworth, M., Blehar, M., Waters, E., \& Wall, S. (1978). Patterns of attachment. Hillsdale, NJ: Erlbaum.

Ambrosini, P. J., Metz, C., Prabucki, K., \& Lee, J. (1989). Videotape reliability of the third revised edition of the K-SADS. Journal of the American Academy of Child and Adolescent Psychiatry, 28, 723-728.

Arad, B. D. (2001). Prenatal features and quality of life in the decision to remove children at risk from home. Child Abuse and Neglect, 25, 47-64.

Armsden, G., Pecora, P. J., Payne, V. H., \& Szatkiewicz, J. P. (2000). Children placed in long-term foster care: An intake profile using the Child Behavior Checklist 4-18. Journal of Emotional and Behavioral Disorders, 8, 49-64.

Bowlby, J. (1960). Grief and mourning in infancy and early childhood. The Psychoanalytic Study of the Child, $15,9-52$.

Bowlby, J. (1969/1982). Attachment and loss: Vol. 1. Attachment. New York: Basic Books.

Carlson, E. A. (1998). A prospective longitudinal study of attachment dissorganization/disorientation. Child Development, 69, 1107-1128.

Carlson, V., Cicchetti, D., Barnett, D., \& Braunwald, K. (1989). Disorganized/disoriented attachment relationships in maltreated infants. Developmental Psychology, 25, 525-531.

Chambers, W., Puig-Antich, J., Hirsch, M., Paez, P., Ambrosini, P., Tabrizi, M. A., et al. (1985). The assessment of prepubertal major depression with the Kiddie-SADS-E. Journal of the American Academy of Child Psychiatry, 21, 695-707.

Cicchetti, D., \& Toth, S. (2000). Developmental processes in maltreated children. In D. J. Hansen (Ed.), Nebraska Symposium on Motivation: Vol. 46. Motivation and child maltreatment (pp. 85-160). Lincoln, NE: University of Nebraska Press.

Clausen, J. M., Landsverk, J., Ganger, W., Chadwick, D., \& Litrownik, A. (1998). Mental health problems of children in foster care. Journal of Child and Family Studies, 7, 283-296.

Connolly, J., \& Doyle, A. (1981). Assessment of social competence in preschoolers: Teachers versus peers. Developmental Psychology, 17, 454-462. dren in care is regarded as notably variable and at times nonexistent in systems that are overwhelmed by large populations of foster children. The intervention services necessary to assist children throughout their stay in foster care must continue to be defined and expanded. Collaborative efforts, including specialized medical, psychological, and academic services in coordination with ongoing school and agency programs, are required to significantly reduce the development of behavior problems and related symptoms while children reside in foster care and beyond.

Costello, A. (1991). Structured interviewing. In M. Lewis (Ed.), Child and adolescent psychiatry: A comprehensive textbook (pp. 463-472). Baltimore, MD: Williams \& Wilkins.

Cummings, E. M., \& Cicchetti, D. (1990). Toward a transactional model of relations between attachment and depression. In M. T. Greenberg, D. Cicchetti, \& E. M. Cummings (Eds.), Attachment in the preschool years (pp. 339-374). Chicago: University of Chicago.

Curtis, P. A. (1999). In P. A. Curtis, G. Dale, Jr., J. C. Kendall, \& J. D. Rockefeller, IV (Eds.), The foster care crisis: Translating research into policy and practice (pp. 1-17). Lincoln, NE: University of Nebraska Press.

Curtis, P. A., Dale, G., Jr., Kendall, J. C., \& Rockefeller, J. D. IV. (1999). The foster care crisis: Translating research into policy and practice. Lincoln, NE: University of Nebraska Press.

Dozier, M. (2002, May). Intervening with young children: Targeting three critical needs. Paper presented at the Irving B. Harris Training Center Forum, St. Paul, MN.

Dozier, M., Stovall, K. C., \& Albus, K. E. (1998). A transactional intervention for foster infants' caregivers. In D. Cicchetti \& S. L. Toth (Eds.), Rochester Symposium on Developmental Psychopathology: Vol. 9. Developmental approaches to prevention and intervention (pp. 195-219). Rochester, NY: University of Rochester Press.

Dozier, M., Stovall, K. C., Albus, K. E., \& Bates, B. (2001). Attachment for infants in foster care: The role of caregiver state of mind. Child Development, 72, 1467-1477.

Egeland, B. (1991a). A longitudinal study of high risk families: Issues and findings. In R. Starr \& D. Wolfe (Eds.), The effects of child abuse and neglect: Issues and research (pp. 33-56). New York: Guilford Press.

Egeland, B. (1991b). From data to definition. Development and Psychopathology, 3, 37-43.

Egeland, B. (1997). Mediators of the effects of child maltreatment on developmental adaptation in adolescence. In D. Cicchetti \& S. L. Toth (Eds.), Rochester Symposium on Developmental Psychopathology: Vol. 8. The effects of trauma on the developmental process (pp. 403-434). Rochester, NY: University Press of Rochester. 
Egeland, B., \& Brunquell, D. (1979). An at-risk approach to the study of child abuse: Some preliminary findings. Journal of the American Academy of Child Psychiatry, 8, 219-235.

Egeland, B., Carlson, E., \& Sroufe, L. A. (1993). Resilience as process. Development and Psychopathology, 5, 517-528.

Egeland, B., \& Carlson, E. A. (2004). Attachment and psychopathology. In L. Atkinson \& S. Goldberg (Eds.), Clinical Implications of Attachment (pp. 27-48). Mahwah, NJ: Erlbaum.

Egeland, B., \& Deinard, A. (1975). The Child Care Rating Scale. Unpublished manuscript, University of Minnesota, Minneapolis.

Egeland, B., \& Sroufe, L. A. (1981). Attachment and early maltreatment. Child Development, 52, 44-52.

Egeland, B., Sroufe, L. A., \& Erickson, M. F. (1983). Developmental consequence of different patterns of maltreatment. Child Abuse and Neglect, 7, 459-469.

Erickson, M., Sroufe, L. A., \& Egeland, B. (1985). The relationship between quality of attachment and behavior problems in preschool in a high risk sample. Monographs of the Society for Research in Child Development, 50 (Serial No. 209), 147-186.

Fanshel, D., Finch, S., \& Grundy, J. (1989). Modes of exit from foster family care and adjustment at time of departure of children with unstable life histories. Child Welfare, 68, 391-402.

Fanshel, D., \& Shin, E. (1978). Child behavior characteristics of foster children. In D. Fanshel \& E. Shin (Eds.). Children in foster care: A longitudinal investigation (pp. 325-372). New York: Columbia University Press.

Garmezy, N. (1993). Children in poverty: Resilience despite risk. Psychiatry, 56, 127-152.

Garmezy, N., \& Masten, A. (1994). Chronic adversities. In M. Rutter, L. Hersov, \& E. Taylor, (Eds.). Child and adolescent psychiatry (3rd ed., pp. 191-208). Oxford: Blackwell.

Halfon, N., Mendonca, A., \& Berkowitz, G. (1995). Health status of children in foster care: The experience of the center for the vulnerable child. Archives of Pediatric and Adolescent Medicine, 149, 386-392.

Harrington, D. M., Block, J. H., \& Block, J. (1978). Intolerance of ambiguity in preschool children: Psychometric considerations, behavioral manifestations, and parental correlates. Developmental Psychology, 14, 242-245.

Heister, M., Carlson, E. A., \& Sroufe, L. A. (1993). The evolution of friendship in preschool, middle childhood, and adolescence: Origins in attachment history. Paper presented at the biennial meeting of the Society for Research in Child Development, New Orleans, LA.

Hochstadt, N., Jaudes, P., Zimo, D., \& Schachter, J. (1987). The medical and psychological needs of children entering foster care. Child Abuse and Neglect, 2, 53-62.

Hulsey, T., \& White, R. (1989). Family characteristics and measures of behavior in foster and non-foster children. American Journal of Orthopsychiatry, 59, 502-509.

Jones, M. D. (1985). A second chance for families: Five years later follow-up of a program to prevent foster care. New York: Child Welfare League of America.

Landsverk, J. (1996, April). The mental health needs of children in foster care: A case of benign neglect? Paper present at the University of Minnesota Foster Care Symposium.
Landsverk, J., \& Garland, A. F. (1999). Foster care and pathways to mental health services. In P. A. Curtis, G. Dale, Jr., J. C. Kendall, \& J. D. Rockefeller, IV (Eds.), The foster care crisis: Translating research into policy and practice. Lincoln, NE: University of Nebraska Press.

Lynch, M., \& Cicchetti, C. (1991). Patterns of relatedness in maltreated and non maltreated children: Connections among multiple representational models. Development and Psychopathology, 3, 207-226.

Maas, H., \& Engler, R. (1959). Children in need of parents. New York: Columbia University Press.

Masten, A. S., \& Garmezy, N. (1985). Risk, vulnerability and protective factors in developmental psychopathology. In B. Lahey \& A. Kazdin (Eds.), Advances in clinical child psychology (Vol. 8, pp.1-52). New York: Plenum Press.

Masten, A. S., \& Wright, M. (1998). Cumulative risk and protection models of child maltreatment. In B. B. R Rossman \& M. S. Rosenberg (Eds.), Multiple victimization of children: Conceptual, developmental, research and treatment issues. Binghamton, NY: Haworth Press.

Matas, L., Arend, R., \& Sroufe, L. A. (1978). Continuity of adaptation in the second year: The relationship between quality of attachment and later competent functioning. Child Development, 49, 547-556.

McCrone, E. R., Egeland, B., Kalkoske, M., \& Carlson, E. A. (1994). Relations between early maltreatment and mental representations of relationships assessed with projective storytelling in middle childhood. Development and Psychopathology, 6, 99-120.

McDonald, T. P., Allen, R. I., Westerfelt, A., \& Piliavin, I. (1996). Assessing the long-term effects of foster care. A research synthesis. Washington, DC: CWLA Press.

McIntyre, A., \& Keesler, T. (1986). Psychological disorders among foster children. Journal of Clinical Child Psychology, 15, 297-303.

Milan, S. E., \& Pinderhughes, E. E. (2000). Factors influencing maltreated children's early adjustment in foster care. Development and Psychopathology, 12, 63-81.

Pianta, R. C., Erickson, M. F., Wagner, N., Kreutzer, T., \& Egeland, B. (1990). Early predictors of referral for special services: Child based measures versus motherchild interaction. School Psychology Review, 19, 240-250.

Pianta, R. C., Sroufe, L. A., \& Egeland, B. (1989). Continuity and discontinuity in maternal sensitivity at 6 , 24 and 42 months in a high risk sample. Child Development, 60, 481-487.

Puig-Antich, J., \& Chambers, W. (1978). The schedule for affective disorders and schizophrenia for school-aged children. New York: New York Psychiatric Institute.

Rutter, M. (1987). Psychosocial resilience and protective mechanisms. American Journal of Orthopsychiatry, 57, 316-331.

Rutter, M. (2000). Children in substitute care: Some conceptual considerations and research implications. Children and Youth Services Review, 22, 685-703.

Shah, C. P. (1974). Psychiatric consultations in a child welfare agency. Canadian Psychiatric Association Journal, 19, 393.

Simms, M., \& Halfon, N. (1994). School performance of children in kinship care. Child Abuse and Neglect, 18 , 587-597.

Sroufe, L. A. (1996). Emotional development: The organization of emotional life in the early years. New York: Cambridge University Press. 
Swire, M., \& Kavaler, F. (1977). The health status of foster children. Child Welfare, 58, 635-653.

Theis, S. (1924). How foster children turn out. New York: State Charities Aid Association.

US Department of Health and Human Services, Administration for Children and Families, Administration on Children, Youth and Families, Children's Bureau. (2003). The AFCARS report. Washington, DC: Government Printing Office.

United States General Accounting Office. (1995). Child welfare: Complex needs strain to capacity. GAO/ HEHS-95-208. Washington, DC: Government Printing Office.

Weinfield, N. S., Sroufe, L. A., Egeland, B., \& Carlson, E. A. (1999). The nature of individual differences in infant-caregiver attachment. In J. Cassidy \& P. Shaver
(Eds.), Handbook of attachment: Theory, research and clinical applications (pp. 73-95). New York: Guilford Press.

Weinstein, E. (1960). The role of placement experiences in mediating the criminal consequences of early childhood victimization. American Journal of Orthopsychiatry, 61, 195-209.

Zima, B. T., Bussing, R., Freeman, S., Yang, X., Belin, T. R., \& Forness, S. R. (2000). Behavior problems, academic skill delays and school failure among schoolaged children in foster care: Their relationship to placement characteristics. Journal of Child and Family Studies, 9, 87-103.

Zuravin, S. J., \& DePanfilis, D. (1997). Factors affecting foster care placement of children receiving protective services. Social Work Research, 21, 34-42. 